\title{
Ring opening reactions of 1,2-epoxides catalyzed by complexes of polyether ligands with metal halides in low polarity solvents. Comparison with heterogeneous systems
}

\author{
Dario Landini, Angelamaria Maia,* and Cristina Pinna \\ Istituto di Scienze e Tecnologie Molecolari del CNR and Dipartimento di Chimica Organica e \\ Industriale dell'Università, Via Golgi 19, I-20133 Milano, Italy \\ E-mail: angelamaria.maia@istm.cnr.it
}

Dedicated to Professor Mieczyslaw Makosza on his $70^{\text {th }}$ birthday

(received 27 Sep 03; accepted 15 Apr 04; published on the web 16 Apr 04)

\begin{abstract}
Metal ion electrophilic catalysis has been revealed in ring opening reactions of 1,2-epoxides 1-5 promoted by complexes of polyethers 6-9 with alkali metal halides $\mathrm{MHal}\left(\mathrm{M}^{+}=\mathrm{Li}^{+}, \mathrm{Na}^{+}, \mathrm{K}^{+}\right.$; $\mathrm{Hal}^{-}=\mathrm{I}^{-}, \mathrm{Br}^{-}$) in solvents of low polarity (chlorobenzene, 1,2-dichlorobenzene). The catalytic effect depends on the Lewis acid character of the cation $\left(\mathrm{K}^{+}<<\mathrm{Na}^{+}<\mathrm{Li}^{+}\right)$as well as on the ligand topology (open-chain $>$ cyclic polyether). Results have been rationalized on the basis of a transition state where the complexed cation $\left(\mathrm{M}^{+} \subset \mathrm{Lig}\right)$ stabilizes the negative charge developing on the oxygen atom of the oxirane ring while favors the nucleophilic attack at the adjacent carbon by the halide anion $\mathrm{Hal}^{-}$.
\end{abstract}

Keywords: Epoxides, oxirane ring opening, metal ion catalysis, solid-liquid phase transfer catalysis, polyether ligands

\section{Introduction}

Macrocyclic and open-chain polyethers (polyethylene glycols, crown ethers, cryptands) are known for their unique ability to specifically bind inorganic salts, giving rise to very stable inclusion complexes. In the complexation process such ligands coordinate, through ion-dipole interactions, a relatively small metal ion $\mathrm{M}^{\mathrm{n}+}$ and transform it into a large, more lipophilic cationic species. This allows the solubilization in non aqueous media of a number of metal salts, as $\left(\mathrm{M}^{\mathrm{n}+} \subset \mathrm{Lig}\right) n \mathrm{Y}^{-}$ion pair, and their transfer from an aqueous to an immiscible organic phase. As a consequence, anion-promoted reactions can be performed in the presence of these ligands under both homogeneous and heterogeneous conditions. ${ }^{1,2-4}$ Whereas in the first case the ligand is used in stoichiometric quantity, only catalytic amounts of it are required in two-phase systems 
like solid-liquid (SL) or liquid-liquid (LL) phase transfer catalysis (PTC). In these complexes the anion is remarkably activated due to the reduced interaction with the bulky complexed cation and little stabilization by the weakly polar medium $\cdot^{1.2-4}$ Reactivity is mainly determined by the ability of the polyether to induce cation-anion separation, increasing in the order: open-chain $<<$ cyclic $<$ bicyclic ligand. In addition, the ligand topology plays a leading role also in reactions where cations are involved in the activation process ("electrophilic catalysis"). ${ }^{1 b, 5}$ We revealed metal ion electrophilic catalysis in nucleophilic substitution reactions of alkyl sulfonates ${ }^{6}$ and, very recently, in demethylation reactions of phosphinic ${ }^{7}$ and phosphate ${ }^{8}$ esters promoted by complexes of polyether ligands with alkali and alkaline-earth metal iodides in solvents of low polarity (chlorobenzene, toluene, 1,2-dichlorobenzene). The catalytic effect increases with increasing Lewis acid character of the cation $\left(\mathrm{K}^{+}<\mathrm{Na}^{+}<\mathrm{Li}^{+} ; \mathrm{Ba}^{2+}<\mathrm{Sr}^{2+}<\mathrm{Ca}^{2+}\right)$ and strictly depends on the ability of the ligand to shield the $\mathrm{M}^{\mathrm{n}+}$ charge. ${ }^{6-8}$ Catalysis is inhibited by cryptands, that effectively "sequester " the metal ion, whereas it is favored by less efficient complexing agents that allow participation of the cation to the reaction (crown ethers, polyethylene glycols). ${ }^{6-8}$

In recent years inorganic salts like alkali metal halides, ${ }^{9} 1$ ithium $^{10}$ and magnesium ${ }^{11}$ iodides and perchlorates, ${ }^{12}$ in weakly polar solvents or supported on silica gel, ${ }^{13}$ have been successfully utilized in the ring opening of epoxides and epoxy alcohols. The products so obtained, under mild conditions and in good yields, often present high regio- and stereo-selectivities, much higher than those obtained with traditional methods. ${ }^{9-13}$

In order to elucidate and quantify the role of the metal ion in these reactions we have performed a kinetic study of ring opening of some representative 1,2-epoxides (1-5) promoted by complexes of polyether ligands (6-10) with alkali metal halides in low polarity anhydrous solvents (chlorobenzene, 1,2-dichlorobenzene) (eq. 1). Comparative studies under solid-liquid PTC conditions and in solid-liquid heterogeneous systems have also been reported (eq. 5).

\section{Results and Discussion}

Kinetic experiments were carried out by reacting a standardized solution $(15 \mathrm{~mL})$ of epoxides 1$5(0.016-0.020 \mathrm{M})$ and tosylamide $(0.03-0.15 \mathrm{M})$ with a standardized solution $(15 \mathrm{~mL})$ of preformed complex $\left(\mathrm{M}^{+} \subset \mathrm{Lig}\right) \mathrm{Hal}^{-}(0.03-0.04 \mathrm{M})$ in the appropriate solvent (chlorobenzene or 1,2 dichlorobenzene) at $60 \pm 0.1^{\circ} \mathrm{C}$ (eq. 1). 


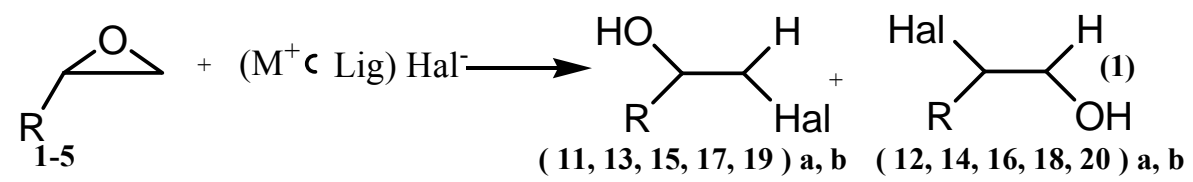

$$
\begin{aligned}
& \mathrm{R}=\mathrm{C}_{10} \mathrm{H}_{12}(\mathbf{1}), \mathrm{C}_{6} \mathrm{H}_{13}(\mathbf{2}), \mathrm{C}_{6} \mathrm{H}_{5}(\mathbf{3}) \mathrm{C}_{6} \mathrm{H}_{5} \mathrm{OCH}_{2}(\mathbf{4}), \mathrm{C}_{6} \mathrm{H}_{5} \mathrm{CH}_{2} \mathrm{OCH}_{2}(\mathbf{5}) \\
& \mathrm{M}^{+}=\mathrm{Li}, \mathrm{Na}^{+}, \mathrm{K}^{+} ; \mathrm{Hal}^{-}=\mathrm{I}^{-}(\mathbf{a}), \mathrm{Br}^{-}(\mathbf{b}) \\
& \left.\mathrm{Lig}=\mathrm{DCH}_{18} \mathrm{C}_{6}(\mathbf{6}), \mathrm{PEG} 400 \mathrm{Me}_{2}(\mathbf{7}), \operatorname{TRIDENT}(\mathbf{8}), \mathrm{Brij} 30 \text { (9), [2.2.2, } \mathrm{C}_{10}\right]
\end{aligned}
$$<smiles>C1CCC2OCCOCCOC3CCCCC3OCCOCCOC2C1</smiles><smiles>CO[C@H]1CCO[C@@H](C)O1</smiles>

DCH18C6 6

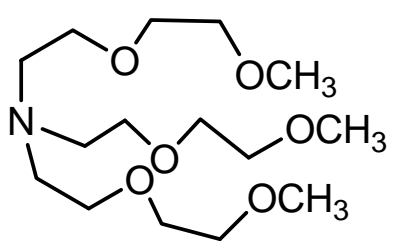

TRIDENT 8

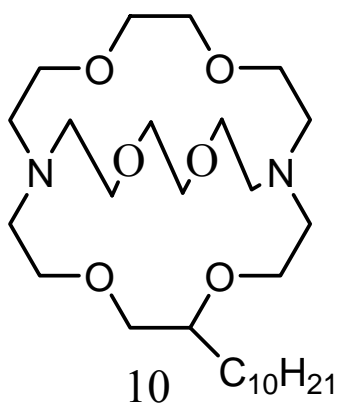

Rates have been measured by potentiometric titration of the complexed nucleophile, iodide or bromide. Under these conditions reactions follow a regular second-order kinetic eq.(2) up to at least 3 half-life times. Results are reported in Tables 1 and 2.

$$
\text { rate }=k[\text { poxide }][\text { complexed Hal }]
$$

The presence of tosylamide $\left(\mathrm{TsNH}_{2}\right)$, in double amount with respect to the epoxide concentration, proved to be essential for obtaining the halohydrines 11-20 in quantitative yields. Otherwise, reactions quickly reach an equilibrium largely shifted $\left(\mathrm{k}_{-1}>>\mathrm{k}_{1}\right)$ towards the reagents (eq. 3). 
Table 1. Second-order rate constants $k\left(\mathrm{M}^{-1} \mathrm{~s}^{-1}\right)$ for the ring opening of epoxides $\mathbf{1}$ and $\mathbf{4}$ by complexes $\left(\mathrm{M}^{+} \subset \operatorname{lig}\right) \mathrm{Hal}^{-}(\mathrm{lig}=\mathbf{6}$ and 7$)$ in chlorobenzene, at $60^{\circ} \mathrm{C}$

\begin{tabular}{ccccc}
\hline epoxide & $\mathrm{M}^{+}$ & $\mathrm{Hal}^{-}$ & ligand & $10^{3} k^{b}\left(\mathrm{M}^{-1} \mathrm{~s}^{-1}\right)$ \\
\hline $\mathbf{1}$ & $\mathrm{Li}^{+}$ & $\mathrm{I}^{-}$ & $\mathbf{7}$ & $24.7(14.9)^{c}$ \\
$\mathbf{1}$ & $\mathrm{Na}^{+}$ & $\mathrm{I}^{-}$ & $\mathbf{7}$ & 0.19 \\
$\mathbf{1}$ & $\mathrm{K}^{+}$ & $\mathrm{I}^{-}$ & $\mathbf{7}$ & ${ }_{d}$ \\
$\mathbf{1}$ & $\mathrm{Li}^{+}$ & $\mathrm{I}^{-}$ & $\mathbf{6}$ & 7.8 \\
$\mathbf{1}$ & $\mathrm{Li}^{+}$ & $\mathrm{Br}^{-}$ & $\mathbf{6}$ & 0.69 \\
$\mathbf{1}$ & $\mathrm{Na}^{+}$ & $\mathrm{I}^{-}$ & $\mathbf{6}$ & $-{ }^{e}$ \\
$\mathbf{1}$ & $\mathrm{K}^{+}$ & $\mathrm{I}^{-}$ & $\mathbf{6}$ & $-{ }^{e}$ \\
$\mathbf{4}$ & $\mathrm{Li}^{+}$ & $\mathrm{I}^{-}$ & $\mathbf{7}$ & 1150 \\
$\mathbf{4}$ & $\mathrm{Na}^{+}$ & $\mathrm{I}^{-}$ & $\mathbf{7}$ & 19.5 \\
$\mathbf{4}$ & $\mathrm{K}^{+}$ & $\mathrm{I}^{-}$ & $\mathbf{7}$ & $-{ }^{-}$ \\
$\mathbf{4}$ & $\mathrm{Li}^{+}$ & $\mathrm{I}^{-}$ & $\mathbf{6}$ & 180 \\
$\mathbf{4}$ & $\mathrm{Li}^{+}$ & $\mathrm{Br}^{-}$ & $\mathbf{6}$ & 20 \\
$\mathbf{4}$ & $\mathrm{Na}^{+}$ & $\mathrm{I}^{-}$ & $\mathbf{6}$ & ${ }^{-}$ \\
$\mathbf{4}$ & $\mathrm{K}^{+}$ & $\mathrm{I}^{-}$ & $\mathbf{6}$ & ${ }^{-}$ \\
\hline
\end{tabular}

${ }^{a}$ A chlorobenzene solution $(30 \mathrm{~mL})$ of epoxide $(1$ or 4$)(0.008-0.010 \mathrm{M})$, tosylamide $(0.015$ $0.075 \mathrm{M})$ and $\left(\mathrm{M}^{+} \subset \mathrm{lig}\right) \mathrm{Hal}^{-}$complex $(0.015-0.020 \mathrm{M}) .{ }^{b}$ Average of at least two determinations. The error in these values is estimated to be $5 \% .{ }^{c}$ Value obtained in 1,2-dichlorobenzene solution. ${ }^{d}$ No reaction after more than 3 days. ${ }^{e}$ No reaction after more than one week.

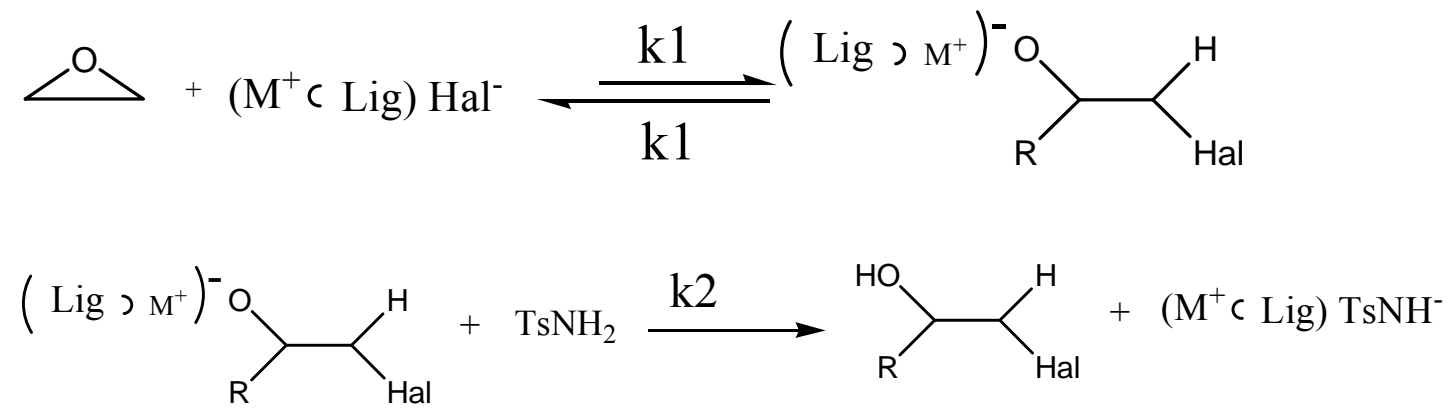

Experiments performed in parallel have shown that $\mathrm{TsNH}_{2}$ takes part to the reaction in a much faster step (eq.4) (acid/base exchange reaction, $\mathrm{k}_{2}>>\mathrm{k}_{1}$ ), subsequent to the opening of the oxirane ring (eq.3), as confirmed by the following results: a) the second-order rate constant $\mathrm{k}$ $\left(\mathrm{M}^{-1} \mathrm{~s}^{-1}\right)$ does not depend on the tosylamide concentration in a relatively wide range $(0.015-0.07$ $\mathrm{M})\left(\right.$ eq.1); b) the corresponding salt $\mathrm{TsNH}^{-} \mathrm{M}^{+}$is quantitatively recovered, together with the tosylamide in excess, at the end of the reaction. 
Table 2. Second-order rate constants $k\left(\mathrm{M}^{-1} \mathrm{~s}^{-1}\right)$ for the ring opening of epoxides 1 and 4 by complexes $\left(\mathrm{Li}^{+} \subset \operatorname{lig}\right) \mathrm{I}^{-}($lig $=\mathbf{6 - 1 0})$ with $\mathrm{LiI}$ in chlorobenzene, at $60^{\circ} \mathrm{C}^{\mathrm{a}}$

\begin{tabular}{|c|c|c|c|}
\hline epoxide & ligand & $10^{3} k^{\mathrm{b}}\left(\mathrm{M}^{-1} \mathrm{~s}^{-1}\right)$ & $k_{\text {rel }}$ \\
\hline 1 & Brij $30(9)$ & 34.5 & 7.7 \\
\hline 1 & $\mathrm{PEG}_{400 \mathrm{Me}_{2}(7)}$ & 24.7 & 5.5 \\
\hline 1 & DCH18C6 (6) & 7.8 & 1.7 \\
\hline 1 & TRIDENT (8) & 4.5 & $\underline{1}$ \\
\hline 4 & $\mathrm{PEG}_{400 \mathrm{Me}_{2}(7)}$ & 1190 & 8.3 \\
\hline 4 & Brij $30(9)$ & 600 & 4.2 \\
\hline 4 & DCH18C6 (6) & 181 & 1.3 \\
\hline 4 & TRIDENT (8) & 144 & $\underline{1}$ \\
\hline 4 & {$\left[2.2 .2, \mathrm{C}_{10}\right](\mathbf{1 0})$} & $-^{c}$ & - \\
\hline
\end{tabular}

${ }^{a}$ Same reaction conditions of Table 1 , footnote $a .{ }^{b}$ Average of at least two determinations. The error in these values is estimated to be $5 \% .{ }^{c}$ No reaction after more than one week.

\section{Metal ion catalysis}

The data of Table 1 reveal the major role played by the metal ion in determining the rate of the ring opening of the epoxides $\mathbf{1}$ and $\mathbf{4}$ promoted by the complexes of alkali metal iodides with ligands 6 and 7. In the case of epoxide 1 with the open chain ligand PEG400Me 7, the reaction rate strongly depends on the cation $\mathrm{M}^{+}$, increasing in the order $\mathrm{K}^{+}<<\mathrm{Na}^{+}<\mathrm{Li}^{+}$. Enhancements

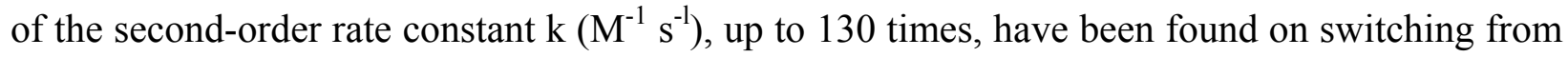
$\mathrm{NaI}$ to the corresponding lithium salt, whereas no reaction after more than three days was observed in the case of KI. In the case of the crown ether DCH18C6 6 the oxirane ring opening was achieved, in only few hours, with the complex $\left(\mathrm{Li}^{+} \subset \mathrm{DCH} 18 \mathrm{C} 6\right) \mathrm{I}^{-}$, but no reaction was observed, even after prolonged times (more than one week), for both NaI and KI complexes .On going from epoxide 1 to phenylglycidol 4 the trend $\left(\mathrm{K}^{+}<<\mathrm{Na}^{+}<\mathrm{Li}^{+}\right)$is unchanged, whereas the reaction rate increases from 23 up to more than 100 times (Table 1).

Results can be explained by assuming a transition state where the complexed metal ion $\left(\mathrm{M}^{+} \subset \mathrm{Lig}\right)$ interacts with both the ion-paired halide anion $\mathrm{Hal}^{-}$and the oxygen of the oxirane ring. In the activation process the ion pair $\left(\mathrm{M}^{+} \subset \mathrm{Lig}\right) \mathrm{Hal}^{-}$reacts following a concerted "push-pull" mechanism in which the cation stabilizes the negative charge developing on the oxygen atom while favors the nucleophilic attack at the adjacent carbon by the halide anion $\mathrm{Hal}^{-}$ ("electrophilic catalysis") (Scheme 1). The higher the interaction between the complexed cation and the ring oxygen the higher the reactivity of the halide ion is expected to be and hence the higher the corresponding reaction rate. The sequence $\left(\mathrm{K}^{+}<\mathrm{Na}^{+}<\mathrm{Li}^{+}\right)$found with both ligands 6 and 7, in particular for PEG400Me , reflects the increasing interaction of the epoxide with the metal ion $\mathrm{M}^{+}$with increasing the Lewis acidity of the cation $\left(\mathrm{K}^{+}<\mathrm{Na}^{+}<\mathrm{Li}^{+}\right){ }^{14}$ 


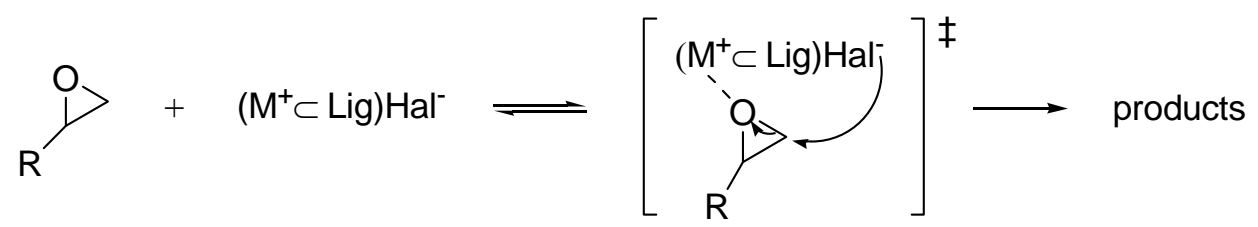

\section{Scheme 1}

The proposed mechanism is confirmed by the higher reaction rates obtained with phenylglycidol 4 if compared with those of epoxide 1 (Table 1). With the epoxide $\mathbf{4}$, in fact, the metal ion is supposed to interact in the transition state not only with the oxirane ring oxygen but also with the oxygen of the side chain (Scheme1). In addition, no opening reaction is found with the quaternary onium salt hexyl ${ }_{4} \mathrm{~N}^{+} \mathrm{I}^{-}$for which no electrophilic assistance is expected (Table 3 ). Finally, the mechanism (mainly of $\mathrm{S}_{\mathrm{N}} 2$ type) is also proved by the fact that all reactions are highly regioselective, giving as the main product the halohydrins $\left(\mathrm{RCHOHCH}_{2} \mathrm{Hal}\right)$ derived from the attack of the halide ion on the less sterically hindered carbon atom of the oxirane ring (see Experimental Section).

An analogous "push-pull" mechanism has recently been proposed by us in nucleophilic substitution reactions promoted by complexes of polyether ligands with alkali metal salts in low polarity solvents. $^{4-6}$

It is worth noting, however, that in the present study the catalytic effect is relevant with lithium iodide but remarkably decreases with the sodium and even more with the potassium salt (Table 1).

\section{Effect of the halide ion}

As reported in Table 1, on changing the lithium iodide with the corresponding bromide, the opening rate of epoxides 1 and $\mathbf{4}$ catalysed by the complexes of crown ether $\mathbf{6}$ in chlorobenzene ( eq 1 ) decreases 11 and 9 times, respectively. The lower reactivity is most likely due to the higher interaction of the complexed cation $\left(\mathrm{Li}^{+} \subset \mathrm{DCH} 18 \mathrm{C} 6\right)$ with the bromide ion that on one hand reduces the catalytic activity of the cation and on the other deactivates the ion-paired anion. Crown ethers, due to their particular topology, are known not realize a great cation-anion separation. ${ }^{3,4}$ As a consequence, by increasing the charge density of cation and/or anion, the ion pair becomes progressively more intimate and hence less reactive. Such a behavior was experimentally confirmed by our previous studies concerning the nucleophilic substitution of alkyl sulfonates by complexes of DCH18C6 6 with lithium halides. ${ }^{6}$ The nucleophilicity sequence obtained with these complexes $\left(\mathrm{I}^{-}>\mathrm{Br}^{-}>\mathrm{CI}^{-}\right)$, opposite to that traditionally known for these anions in the gas phase and in dipolar aprotic media, was just attributed to the deactivation of the halide anion, increasing in the order : $\mathrm{I}^{-}<\mathrm{Br}^{-}<\mathrm{Cl}^{-}{ }^{6}$ b

\section{Effect of the ligand}

The effect of the ligand on the reaction rate was studied by reacting the epoxide ( $\mathbf{1}$ or $\mathbf{4}$ ) with a 
series of $\left(\mathrm{Li}^{+} \subset \mathrm{Lig}\right) \mathrm{I}^{-}$complexes, where $\mathrm{Lig}=\mathbf{6 - 1 0}$ (eq.1). Results, reported in Table 2, show that open chain ligands such as PEG400Me 7 or Brij 309 (a commercially available mixture of the tetraethylene glycol monododecyl ether) have a catalytic activity higher, up to more than 8 times, than that of other open chain (TRIDENT 8) or cyclic (DCH18C6 6) polyethers. The difference is even dramatic if the complex of cryptand [2.2.2, $\left.\mathrm{C}_{10}\right] \mathbf{1 0}$ is used. In this case indeed no opening reaction was observed after more than one week. The data can be explained in terms of the different ability of the ligand to shield the metal ion charge in the transition state (Scheme 1). Whereas powerful complexing agents, such as $\left[2.2 .2, \mathrm{C}_{10}\right] \mathbf{1 0}$, activate the ion-paired anion but inhibit metal ion electrophilic catalysis, less efficient anion activators (crown ether 6, PEG400Me 27 or Brij30 9) favor the catalysis. ${ }^{6-8}$ In particular, with the latter two (7 and 9) the lower anion activation realized by the ligand is largely compensated by a higher participation of the cation in the activation process. As a consequence, the appropriate choice of the polyether can further increase the rate of the epoxide opening (eq.1).

\section{Comparison with solid - liquid heterogeneous systems}

To gain quantitative comparison with heterogeneous conditions the reaction (eq.1) was repeated in solid-liquid two-phase systems by magnetically stirring a chlorobenzene solution of epoxide 4 $(0.01 \mathrm{M})$ and tosylamide $(0.02 \mathrm{M})$ with two molar equivalents of the solid salt (LiI) in the presence of catalytic amounts (0.2 mol equiv.) of ligand (6 or 7) (SL-PTC) as well as in the absence of catalyst (SL) (eq. 5). In both systems the reaction was followed by TLC monitoring of the disappearance of the epoxide in the organic phase. The data of Table 3 show that the reaction time decreases, up to 10 times, when the solid salt-chlorobenzene two-phase system is added with catalytic amounts of ligand (SL-PTC conditions). Interestingly, PEG400Me 7 demonstrated a catalyst much better than crown ether $\mathbf{6}$. With this open chain polyether, in fact, the reaction is more than 5 fold faster than that with the cyclic ligand $\mathbf{6}$ (Table 3 ).

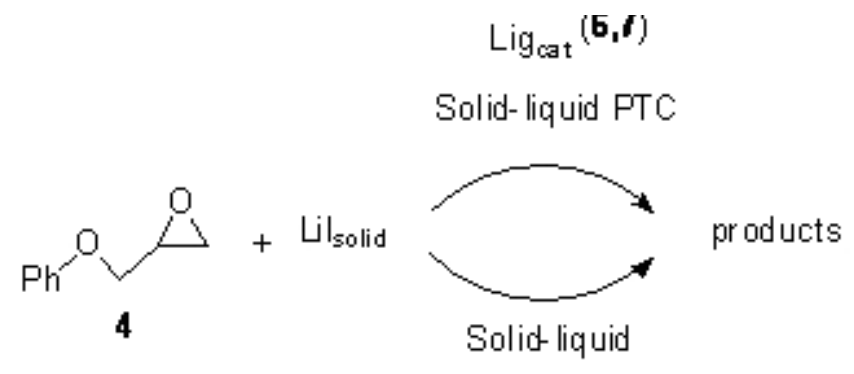

solvent: chlorobenzene 
Table 3. Reaction times (h) for the ring opening of epoxide 4 by $\mathrm{Q}^{+} \mathrm{I}^{-}$in homogeneous and heterogeneous systems, at $60 \pm 0.1^{\circ} \mathrm{C}$

\begin{tabular}{|c|c|c|c|}
\hline \multirow{3}{*}{$\mathrm{Q}^{+} \mathrm{I}^{-}$} & \multicolumn{3}{|c|}{ Reaction time $^{a}(\mathrm{~h})$} \\
\hline & \multirow[t]{2}{*}{$\begin{array}{c}\text { Homogeneous conditions }{ }^{b} \\
\text { (chlorobenzene) }\end{array}$} & \multicolumn{2}{|c|}{$\begin{array}{l}\text { Heterogeneous conditions } \\
\text { (chlorobenzene-solid LiI) }\end{array}$} \\
\hline & & SL-PTC ${ }^{c}$ & $\mathrm{SL}^{d}$ \\
\hline$\left(\mathrm{Li}^{+} \subset \mathrm{PEG} 400 \mathrm{Me}_{2}\right) \mathrm{I}^{-}$ & 1.5 & 6 & \\
\hline$\left(\mathrm{Li}^{+} \subset \mathrm{DCH} 18 \mathrm{C} 6\right) \mathrm{I}^{-}$ & 8 & 31.5 & \\
\hline LiI & & & 56 \\
\hline $\mathrm{Hexyl}_{4} \mathrm{~N}^{+} \mathrm{I}^{-}$ & $\_^{e}$ & & \\
\hline
\end{tabular}

${ }^{a}$ Conversions $\geq 95 \%$, by TLC analysis. ${ }^{b}$ Same reaction conditions of Table 1 , footnote $a .{ }^{c} \mathrm{~A}$ chlorobenzene solution $(30 \mathrm{~mL})$ of epoxide $4(0.01)$, tosylamide $(0.02 \mathrm{M})$ and ligand $(0.02 \mathrm{M})$ with two mol equiv. of LiI as a solid phase. ${ }^{d}$ A chlorobenzene solution $(30 \mathrm{~mL})$ of epoxide $4(0.01 \mathrm{M})$ and tosylamide $(0.02 \mathrm{M})$ with two mol equiv. of LiI as a solid phase. ${ }^{e}$ No reaction after more than two weeks.

As a consequence, the present results clearly indicate the solid-liquid phase-transfer system catalysed by PEG400Me 7 as the best one for obtaining the ring opening of 1,2-epoxides under mild conditions and in high yields. The possibility of exploiting the latter procedure for synthetic applications is currently under investigation in our laboratories.

\section{Conclusions}

The results as a whole provide strong evidence for involvement of the metal ion ("electrophilic catalysis") in the oxirane ring opening of 1,2-epoxides $\mathbf{1 - 5}$ promoted by complexes of polyethers 6-9 with alkali metal halides MHal (Tables 1 and 2). The catalytic effect mainly depends on the charge density of the cation ( defined as $\mathrm{M}^{+}$charge/ionic radius ratio ), increasing in the order $\mathrm{K}^{+}$ $<<\mathrm{Na}^{+}<\mathrm{Li}^{+}$, but also the ligand topology plays a crucial role in determining the reaction time (open chain better than cyclic ligand). In these systems the ligand solubilizes the salt in the low polarity solvent by formation of stable inclusion complexes in which the cation, even if partially shielded by the polyether oxygens, can still interact with the epoxide in the activation process (Scheme 1).

Finally, it is worth noting that, from a practical point of view, solid-liquid phase-transfer catalysis (SL-PTC) conditions have proved to be the best reaction system (Table 3). Interestingly, open chain polyethers, in particular PEG400Me 7 and Brij 30 9, are the catalysts of choice because they are less expensive than crown ethers and also have the same regioselectivity and the highest catalytic activity. 


\section{Experimental Section}

General Procedures. Potentiometric titrations were carried out with a Metrohm 670 Titroprocessor by using a combined silver electrode isolated with a potassium nitrate bridge. Karl-Fischer determinations were performed with a Metrohm $684 \mathrm{KF}$ coulometer. ${ }^{1} \mathrm{H}$ NMR spectra were recorded in $\mathrm{CDCl}_{3}$ on Bruker $\mathrm{AC} 300$ and $\mathrm{AMX} 300$ spectrometers using $\mathrm{CHCl}_{3}$ as external reference. The TLC analysis was performed by using silica gel and petroleum ether (PE), b.p. $40-60^{\circ} \mathrm{C}$.

\section{Materials and solvents}

Tetrahexylammonium iodide, p-toluensulfonamide, ligands DCH18-crown-6 6 (mixture of isomers), PEG400Me $\mathrm{Me}_{2}$ 7, TRIDENT 8, Brij 309 and cryptand 10 were commercial products, utilized as purchased. Alkali metal halides, AnalaR grade commercial products, were ground and then dehydrated in an oven at $110-120^{\circ} \mathrm{C}$ under vacuum for several hours. In all cases the water content is $\leq 0.05 \mathrm{~mol}$ of $\mathrm{H}_{2} \mathrm{O}$ per mol of salt (Karl Fischer titration). Dry ( Fluka ) chlorobenzene and 1,2-dichlorobenzene $\left(\mathrm{H}_{2} \mathrm{O} \leq 15 \mathrm{ppm}\right)$ were used.

Epoxides 1-4 are commercial products, purified by distillation and kept over molecular sieves. Benzylglycidol (5) was prepared according to a previously reported procedure: bp $68^{\circ} \mathrm{C}$ $(0.01 \mathrm{~mm}), \mathrm{n}^{20}{ }_{\mathrm{D}}=1.5172\left[\right.$ lit. $^{15}$ bp $\left.62-63^{\circ} \mathrm{C}(0.001 \mathrm{~mm}), \mathrm{n}^{20}{ }_{\mathrm{D}}=1.5148\right]$.

\section{Kinetic measurements}

In a typical procedure, a standardized solution $(15 \mathrm{~mL})$ of epoxide 1-5 $(0.016-0.020 \mathrm{M})$ and $\mathrm{TsNH}_{2}(0.03-0.15 \mathrm{M})$ was added to a standardized solution $(15 \mathrm{~mL})$ of complexed MHal (0.03$0.04 \mathrm{M})$ in a $50 \mathrm{~mL}$ flask thermostated at $60 \pm 0.1^{\circ} \mathrm{C}$. Samples $(2-5 \mathrm{~mL})$, withdrawn periodically, were quenched in ice-cold $\mathrm{MeOH}(50 \mathrm{~mL})$, and the unreacted halide $\mathrm{Hal}^{-}$was potentiometrically titrated with $0.01 \mathrm{~N} \mathrm{AgNO}_{3}$. The second-order rate constants were evaluated using a leastsquares computer program from the eq $1 /([\mathrm{Bo}]-[\mathrm{Ao}]) \ln ([\mathrm{B}][\mathrm{Ao}] /[\mathrm{A}][\mathrm{Bo}])=\mathrm{kt}$, where $\mathrm{A}=$ epoxide and $\mathrm{B}=$ complexed halide or viceversa. All rates involved at least eight samplings and gave correlation coefficients of 0.995 or better. The solutions of preformed complexes of 6-10 were prepared by magnetically stirring a standardized solution $(30 \mathrm{~mL})$ of ligand in the organic solvent (chlorobenzene, 1,2-dichlorobenzene) (0.05-0.1 M) with the appropriate quantity of salt MHal (0.9-1.3 mol per mol of ligand) as a solid phase, in a flask thermostated at $60 \pm 0.1^{\circ} \mathrm{C}$. The heterogeneous system was stirred for 1-3 $\mathrm{h}$ and then kept without stirring for an additional10 min to allow good separation of the two phases. Aliquots $(5-8 \mathrm{~mL})$ of the organic phase were centrifuged and samples $(2-5 \mathrm{~mL})$ were withdrawn and titrated with $0.01 \mathrm{~N} \mathrm{AgNO}_{3}$. Potentiometric titrations of cryptates of $\mathbf{1 0}$ were performed in acid medium $\left(\mathrm{HNO}_{3}\right)$ in order to avoid the simultaneous titration of the free ligand. 


\section{Reaction Products}

In a $60 \mathrm{~mL}$ flask, thermostated at $60 \pm 0.1^{\circ} \mathrm{C}$, a solution $(15 \mathrm{~mL})$ of preformed complex $\left(\mathrm{Li}^{+} \subset\right.$ lig) $\mathrm{Hal}^{-}(0.04 \mathrm{M})$ was added to a solution $(35 \mathrm{~mL})$ of epoxide 1-5 $(0.02 \mathrm{M})$ and $\mathrm{TsNH}_{2}(0.04 \mathrm{M})$ and then magnetically stirred until the disappearance of the substrate $\left(\mathrm{TLC}\right.$ analysis, $\mathrm{Et} \mathrm{H}_{2} \mathrm{O} / \mathrm{PE}=$ 2/1). The reaction mixture was washed with brine and dryed. After evaporation of the solvent under vacuum ( $10 \mathrm{mmHg}$ ), the crude was purified by flash chromatography (silica gel 240-400 mesh, $\left.\mathrm{Et}_{2} \mathrm{O} / \mathrm{PE}=1 / 1\right)$. The pure products were characterized by ${ }^{1} \mathrm{H} \mathrm{NMR}$ analysis and compared with the literature data. ${ }^{10,16-18}$

Substrate, $\left(\mathrm{Li}^{+} \subset\right.$ lig) $\mathrm{Hal}^{-}$, reaction time, product, yield, physical properties are as follows: 1,2epoxydodecane (1), $\left(\mathrm{Li}^{+} \subset 7\right) \mathrm{I}^{-}, 8 \mathrm{~h}, 1$-iodo-dodecan-2-ol (11a) ${ }^{17} 83 \%,{ }^{1} \mathrm{H}$ NMR $\left(\mathrm{CDCl}_{3}\right) \delta 0.86$ $(\mathrm{t}, 3 \mathrm{H}, \mathrm{J}=7.0 \mathrm{~Hz}), 1.25-1.55(\mathrm{~m}, 18 \mathrm{H}), 2.2(\mathrm{~s}, 1 \mathrm{H}), 3.19-3.53(\mathrm{~m}, 3 \mathrm{H}) .1$,2-epoxyoctane (2), $\left(\mathrm{Li}^{+} \subset 7\right) \mathrm{I}^{-}, 4 \mathrm{~h}, 1$-iodo-octan-2-ol (13a) ${ }^{10,16} 81 \%,{ }^{1} \mathrm{H}$ NMR $\left(\mathrm{CDCl}_{3}\right) \delta 0.87(\mathrm{t}, 3 \mathrm{H}, \mathrm{J}=7.0 \mathrm{~Hz}), 1.26-$ $1.30(\mathrm{~m}, 10 \mathrm{H}), 2.24(\mathrm{~s}, 1 \mathrm{H}), 3.18-3.53(\mathrm{~m}, 3 \mathrm{H})$; 1,2-epoxystirene (3), ( $\left.\mathrm{Li}^{+} \subset 7\right) \mathrm{I}^{-}, 4 \mathrm{~h}, 2$-iodo-1phenylethanol ( 15a), ${ }^{16} 70 \%,{ }^{1} \mathrm{H}$ NMR $\left(\mathrm{CDCl}_{3}\right) \delta 2.02(\mathrm{~s}, 1 \mathrm{H}), 3.76(\mathrm{~d}, 2 \mathrm{H}), 4.78(\mathrm{t}, 1 \mathrm{H}, \mathrm{J}=5.0$ $\mathrm{Hz}$ ) 7.17-7.35 (m, 5H); 1,2-epoxystirene (3), $\left(\mathrm{Li}^{+} \subset \mathbf{6}\right) \mathrm{Br}^{-}, 96 \mathrm{~h}, 2$-bromo-1-phenylethanol (15 b), ${ }^{16}$ $56 \%,{ }^{1} \mathrm{H} \mathrm{NMR}\left(\mathrm{CDCl}_{3}\right) \delta 2.6(\mathrm{~d}, 1 \mathrm{H}, \mathrm{J}=3.1 \mathrm{~Hz}), 3.53(\mathrm{dd}, 1 \mathrm{H}), 3.63(\mathrm{dd}, 1 \mathrm{H}), 4.93(\mathrm{dd}, 1 \mathrm{H}) 7.34-$ 7.39 (m 5H); 2-bromo-2-phenylethanol (16b), ${ }^{16} 28 \%, \delta 2.2(\mathrm{~s}, 1 \mathrm{H}), 3.93(\mathrm{dd}, 1 \mathrm{H}), 4.04(\mathrm{dd}, 1 \mathrm{H})$, 5.04 (dd, 1H), 7.36 (m, 5H); 1,2-phenylglycidol (4), (Li $\left.{ }^{+} \subset 7\right) \mathrm{I}^{-}, 1.5 \mathrm{~h}, 1$-phenoxy-3-iodo-propan2-ol ( 17a), ${ }^{16} 78 \%,{ }^{1} \mathrm{H}$ NMR $\delta 3.1(\mathrm{~s}, 1 \mathrm{H}), 3.48$ (d, 2H, J = 5.0 Hz), 4.06 (q, 1H, J=2.0 Hz), 4.13 $(\mathrm{d}, 2 \mathrm{H}, \mathrm{J}=7.0 \mathrm{~Hz}), 6.78-6.90(\mathrm{~m}, 3 \mathrm{H}), 7.36$ (m, 2H) ; 1,2- benzylglycidol (5), $\left(\mathrm{Li}^{+} \subset 7\right) \mathrm{I}^{-}, 1.5 \mathrm{~h}, 1-$ benzyloxy-3-iodo-propan-2-o1 (19a), ${ }^{18} 75 \%,{ }^{1} \mathrm{H}$ NMR $\left(\mathrm{CDCl}_{3}\right) \delta 3.4(\mathrm{~s}, 1 \mathrm{H}), 3.28-3.34$ (m, 2H, J $=10.2 \mathrm{~Hz}), 3.57-3.59$ (d, 2H, J = 5.5 Hz), 3.75-3.80 (m, 1H), $4.56(\mathrm{~s}, 2 \mathrm{H}), 7.25-7.34(\mathrm{~m}, 5 \mathrm{H})$.

\section{Acknowledgments}

We gratefully acknowledge the support of this research by CNR and MURST.

\section{References}

1. (a) Poonia, N. S.; Bajaj, A. V. Chem. Rev. 1979, 79, 389. (b) Lehn, J. M. Pure Appl. Chem. 1980, 52, 2303. (c) Gokel, G. W. Chem. Soc. Rev. 1992, 39. (d) Marrone, T. J.; Merz Jr, K. M. J. Am. Chem. Soc. 1995, 117, 779. (e) Izatt, R. M.; Pawlak, K.; Bradshaw, J. S. Chem. Rev. 1991, 91, 1721.

2. Landini, D.; Maia, A.; Montanari, F.; Tundo, P. J. Am. Chem. Soc. 1979, 101, 2526. Landini, D.; Maia, A.; Montanari, F.; Pirisi, F. M. J. Chem. Soc., Perkin Trans. 2 1980, 46. Landini, D.; Maia, A.; Podda, G.; Secci, D.; Yan, Y. M. J. Chem.Soc., Perkin Trans. 2 1992, 1721.

3. Maia, A. Pure Appl. Chem. 1995, 67, 697. 
4. Landini, D.; Maia, A.; Penso, M. Comprehensive Supramolecular Chemistry; Lehn, J. M. Ed.; Pergamon Press, Oxford, 1996; Vol. 1, Chapter 11, pp 417-464.

5. Lefour, J. M.; Loupy, A. Tetrahedron 1978, 34, 2597.

6. (a) Gobbi, A.; Landini, D.; Maia, A.; Secci, D. J. Org. Chem. 1995, 60, 5954. (b) Gobbi, A.; Landini, D.; Maia, A.; Penso, M. J. Chem. Soc., Perkin Trans 219962505.

7. Albanese, D.; Landini, D.; Maia, A. J. Org. Chem. 2001, 66, 3249.

8. Landini, D.; Maia, A.; Pinna, C. J. Chem. Soc., Perkin Trans 2 2001, 2314.

9. Bajwa, J.; Anderson, R. C. Tetrahedron Lett. 1991, 32, 3021 and references therein.

10. Bonini, C.; Giuliano, C.; Righi, G.; Rossi, L. Syn. Comm. 1992, 22, 1863. Infante, I.; Bonini, C.; Lelj, F.; Righi, G. J. Org. Chem. 2003, 68, 3773.

11. Bonini, C.; Righi, G.; Sotgiu, G. J. Org. Chem. 1991, 56, 6206.

12. Azzena, F.; Calvani, F.; Crotti, P.; Gardelli, C.; Macchia, F.; Pineschi, M. Tetrahedron, 1995, 51, 10601.

13. Kotsuki, H.; Shimanouchi, T.; Ohshima, R.;Fujiwara, S. Tetrahedron 1998, 54, 2709.

14. Pearson, R. G. Coord. Chem. Rev. 1990, 100, 403.

15. Amisuzzaman, A. K. M.; Owen, L. N. J. Chem. Soc. C 1967, 1021.

16. Sharghi, H.; Massah, A. R.; Eshghi, H.; Niknam, K. J. Org. Chem. 1998, 63, 1455.

17. Kuroboshi, M.; Hiyama, T. Bull. Chem. Soc. Jpn. 1995, 68, 1799.

18. Adiyaman, M.; Khanapure, S. P.; Hwang, S. W.; Rokach, J. Tetrahedron Lett. 1995, 36, 7367. 